\title{
Renewable Energy based Green Power Generation for Rural Electrification
}

\author{
Vinod S. Patil, Gopalkrishna D. Kamalapur
}

\begin{abstract}
A major challenge for developing countries is access to electricity in rural area for accelerating its growth. There are significant impediment from the utilities to extend either improved service to the rural user or provide extended hours of supply through conventional grid supply. In developing countries, the most significant challenges are technologies used to upgrade and methods for electrification, which results in poor reliability of supply and high distribution losses, leading to hindering both economic and social development, so energy planners have suggested a hybrid energy system for the electrification of rural areas. This study investigates green energy based integrated generation for rural loads. This proposed system can orchestrate with the grid as well as with the renewable energy-based generator. The wind energy has a natural variance, to satisfy the energy demand during the nocturnal and overcast period a complementary renewable energy generator is critical, or an energy storage mechanism is needed to meet the energy demand. This type of pooled exploitation and interconnection is used to improve the reliability and resilience of the grids. The integration of distributed and clean energy resource like wind generation will reduce fossil fuel emissions and provides electricity in areas which are limitedly served by unified electrical infrastructure. Hence, it is expected to develop/modify technologies available for harnessing renewable energy sources. A MATLAB/Simulink is used to build a model for a grid-wind based integrated generation. Results obtained from MATLAB/Simulink are a close match with a practical system.
\end{abstract}

Keywords: Renewable integration, Distributed energy, Synchronization, Grid.

\section{INTRODUCTION}

Green Energy Resources like solar, wind and tidal are getting developed to surrogate for future energy needs because they are non-depletable location-reliant, nonpolluting, and impending sources of unconventional energy. India is a sovereign state of continental magnitude and this helps to harmonize the variability in yield of green energy sources located in few sectors by amalgamating them into all India grids[1].

Revised Manuscript Received on February 05, 2020.

* Correspondence Author

Vinod Shankargouda Patil*, Assistant Professor, Department of Electrical and Electronics Engineering, Jain College of Engineering, Belagavi, Karnataka, India.

Gopal krishna Dhruvaraj Kamalapur, Professor, Department of Electrical and Electronics Engineering, SDM College of Engineering and Technology, Dharwad, Karnataka, India.

(c) The Authors. Published by Blue Eyes Intelligence Engineering and Sciences Publication (BEIESP). This is an open access article under the CC BY-NC-ND license (http://creativecommons.org/licenses/by-nc-nd/4.0/)
With increasing awareness of limited availability of fossil fuels, high cost of fossil fuels liberation of greenhouse gases to the atmosphere leads to high environmental impact and fear that the fossil fuels will get exhausted in the near century leads to identification and utilization of renewable energy sources like wind, tidal, solar etc. Hence, it is expected to develop/modify technologies available for harnessing renewable energy sources. The Renewable Energy Conversion System (RECS) will effectively reduce the requirement of fossil fuel-based conventional power generation or expansion of power generation and transmission which are limited due to locally available resources and environmental restrictions to have proper growth and social progress. When the renewable energy conversion system is integrated into the power system, it minimizes the ecological and socio-economic impact.

The economic outlook of these green energy technologies is adequately capable of including them for getting considerable power production capability in the budding nation like India. A green energy production fusion of two or more energy sources along with appropriate conversion techniques/systems, a power conditioning device, a smart controller and a flexible energy storage system. These fused energy conversion systems are becoming trendy in the sparsely populated region where power generation is possible due to advancements in green energy technologies. Exploratory investigation and advancement work in solar, wind and other renewable energy adaptation technologies are required to prolong, improve their performance, establishing techniques for precisely predicting their output and unfailingly integrating them with other conventional energy generating sources.

Concatenation of green energy conversion system has to turn out to be very important. To comprehend the integration of these systems through the power electronics interface with the accessible electric power systems networks in unison with high-frequency switching of power electronic interface is a severe issue in power quality while integrating[2]. This has to be dealt with the help of custom power devices interfaces. This type of grid interactive system offers various benefits like the ability to provide supplementary services, increased energy efficiency, increased functionality through superior power quality and voltage/VAR support, better electrical system reliability by reducing the fault contributions, and flexibility in operations with an assortment of other energy sources.Green energy resources like solar and wind are going to become an alternative for future energy needs. India is a nation of colossal size and this helps to balance the erratic output of green energy sources located in few states by integrating them into all India grids[2]. As on March 31, 2012 the gridconnected power generation from green energy sources is 24914 MW i.e. around $12.1 \%$ of the total installed energy capacity[3]. 
Further Ministry of New and Renewable Energy (MNRE), the Indian government is targeting to achieve $20000 \mathrm{MW}$ grid interactive powers through solar and $38500 \mathrm{MW}$ from wind by 2022[4].

\section{GREEN ENERGY GENERATOR} further power obtained from wind generation is integrated with a grid the power derived from fused power production and its power quality issues along with mitigation techniques is discussed in this work. The Permanent Magnet Synchronous Generator based green energy generating mechanism is identified and below work is carried out.

\section{A. Wind Turbine}

Wind power harvesting has been of concern to humans for a long time. For several centuries, wind turbines were used and literally millions of units were put into operation. Because of variations in atmospheric pressure, the wind is created. There is a variation in atmospheric pressure due to air moving from the high pressure area to the lower pressure region resulting in distinct wind speeds. Worldwide, the two main dominant variables for large-scale wind model are the unequal temperature between the equator and the poles (gap in the absorption of thermal confinement due to buoyancy stresses) and the planet's rotation. A wind generator is a unit that transforms the energy in the air into electricity as demonstrated in the air into electricity as demonstrated in the Fig 1

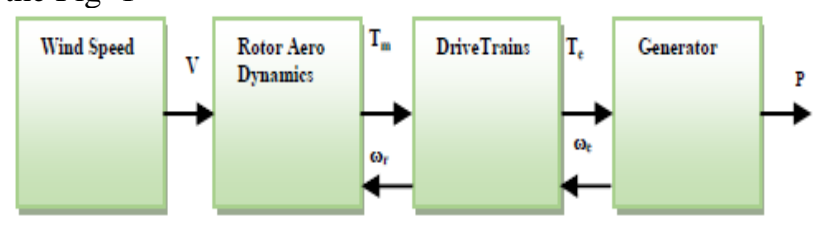

Fig. 1. General Schema of Wind Turbine System

\section{B. Energy content in the wind}

Kinetic energy, in a piece of air mass, goes through the turbine, is the aerodynamic energy that is obtainable through the wind. Far upstream, at the Machine and far downstream the wind mass flow rate is also supposed to be consistent[5]. To calculate the mathematical links,

Let,

$\mathrm{P}_{\text {wind }}=$ Power contained in the wind

$\mathrm{V}=$ wind velocity in $\mathrm{m} / \mathrm{s}$

$\rho=$ Air density in $\mathrm{kg} / \mathrm{m} 3$

$\mathrm{D}=$ diameter of the rotor in $\mathrm{m}$

$\mathrm{A}=$ area swept by blades in $\mathrm{m}^{2}$

$\mathrm{M}=$ Mass of moving air in $\mathrm{kg}$

$\mathrm{d}=$ distance travelled by air

$\beta=$ blade pitch angle in degrees

$\mathrm{C}_{\mathrm{p}}=$ Power coefficient

$\mathrm{N}=$ rotational speed in rpm

$\omega_{\mathrm{m}}=$ angular velocity radian/sec

$\mathrm{R}=$ Radius of the rotor in meters

$\lambda=$ Tip speed ratio

$\mathrm{T}_{\mathrm{m}}=$ Mechanical torque in $\mathrm{Nm}$

$\mathrm{T}_{\mathrm{e}}=$ Electrical torque $\mathrm{Nm}$

The kinetic energy of wind stream passing through the turbine rotor is
A Green energy-based generation is studied and simulated,

and

$$
K E=\frac{1}{2} M V^{2}
$$

Hence,

$$
M=\rho A d
$$

$$
\begin{gathered}
\mathrm{KE}=\frac{1}{2} \rho \mathrm{Ad} \mathrm{V}^{2} \\
\mathrm{P}_{\text {wind }}=\frac{\mathrm{KE}}{\mathrm{t}} \\
\mathrm{P}_{\text {wind }}=\frac{\frac{1}{2} \rho \mathrm{Ad} \mathrm{V}^{2}}{\mathrm{t}} \\
P_{\text {wind }}=\frac{1}{2} \rho A d V^{3}
\end{gathered}
$$

Equationno 3 is implemented in MATLAB/Simulink environment with wind velocity varying between $0 \mathrm{~m} / \mathrm{s}$ to $20 \mathrm{~m} / \mathrm{s}$ as shown in Fig. 2

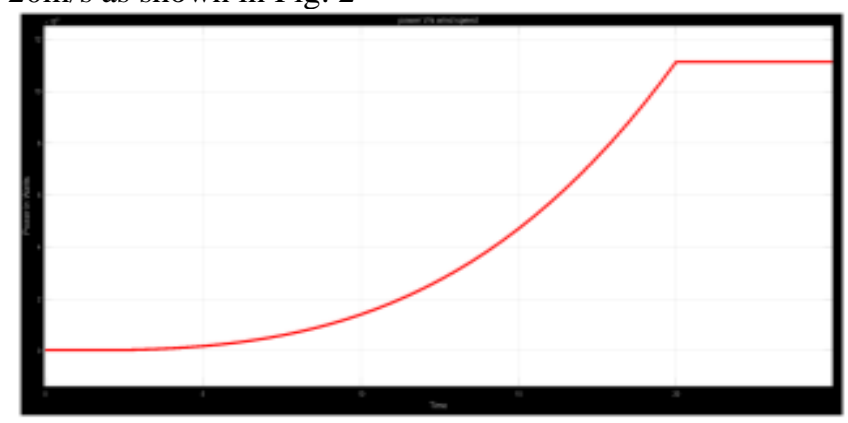

Fig. 2. Power Contained in wind

The $(\beta)$ blade pitch angle is defined as the angle linking the plane of revolution and the blades cross-section chord. The $(\lambda)$, tip speed ratio, is described as that of the ratio between the speed of the tips of the blades of a turbine and the speed of the wind.

$$
\lambda=\frac{\text { Tip speed of the blade }}{\text { windspeed }}=\frac{\omega_{\mathrm{m}} \mathrm{R}}{\mathrm{V}}
$$

where,

$$
\omega_{\mathrm{m}}=\frac{2 \pi \times \mathrm{N}}{60}
$$

The wind power can be restructured with the energy coefficient and pitch angle of the blade depicted by the equation,

$$
\mathrm{P}_{\text {wind }}=\frac{1}{2} \rho \mathrm{AdV}^{3} \mathrm{C}_{\mathrm{p}}(\lambda, \beta)
$$

The power coefficient is dependent on tip speed ratio and pitch angle further it is a ratio of actual power output to the aerodynamic power input of the turbine it can be represented by equation 7 and modeled in Fig 3[6].

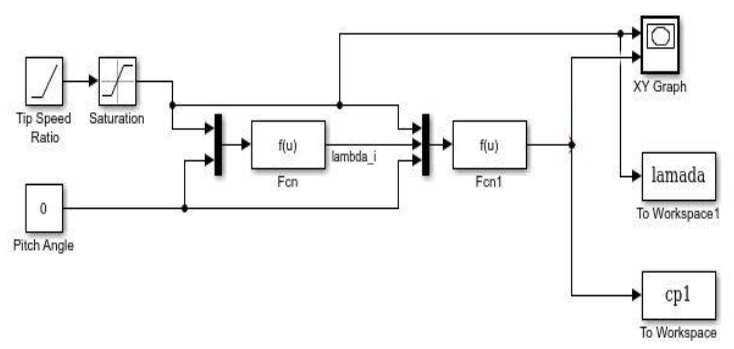

Fig.3.Simulink model of $\mathrm{Cp}$ 


$$
C_{p}(\lambda, \beta)=C_{1}\left(\frac{C_{2}}{\lambda_{1}}-C_{3} \beta-C_{4}\right) e^{\frac{C_{5}}{\lambda_{i}}}+
$$

$$
\mathrm{C}_{6} \lambda
$$

Where

$$
\frac{1}{\lambda_{i}}=\frac{1}{1+0.08}-\frac{0.035}{1+\beta^{3}}
$$

or

$$
C_{p}=\frac{P_{\text {Turbine }}}{P_{\text {wind }}}
$$

The coefficient $\mathrm{C}_{1}$ to $\mathrm{C}_{6}$ are $\mathrm{C}_{1}=0.5176, \mathrm{C}_{2}=116, \mathrm{C}_{3}=$ $0.4, C_{4}=5, C_{5}=21$ and $C_{6}=0.0068[7]$

The power coefficient characteristics are obtained for various values of the pitch angle $\beta$, as illustrated in Fig.4

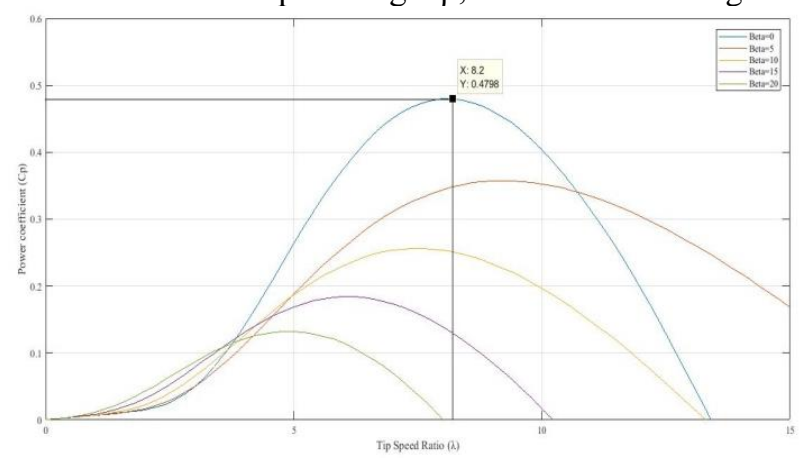

Fig.4.Power Coefficient V/s Tip speed Ratio Characteristics of wind turbine

The peak value of $C_{p}\left(C_{p \max }=0.48\right)$ obtained at $\beta=0^{0}$ and for $\lambda=8$.2.using equations 7

$$
\mathrm{P}_{\max }=\frac{1}{2 \lambda_{\mathrm{opt}}^{3}} \rho \pi \mathrm{R}^{5} \omega_{\mathrm{opt}}{ }^{3} \mathrm{C}_{\mathrm{pmax}}
$$

This equation 8 shows the correlation between turbine power and turbine velocity at peak power. Also, turbine power should not be greater than the generators rated power at all. Once rated power is reached at rated wind speed, power output is being limited. The mechanical actuator is used in the variable speed wind turbine to change the pitch angle of the blades, thus reducing the power coefficient and thereby limiting the power value[9].

The mechanical torque $\left(\mathrm{T}_{\mathrm{m}}\right)$ can be expressed as in equation 9 and modeled in SIMULINK, as shown in Fig.5 resulting in torque, as shown in Fig.6

$$
\mathrm{T}_{\mathrm{m}}=\frac{\mathrm{P}_{\text {wind }}}{\omega}=\frac{\frac{1}{2} \rho \pi \mathrm{r}^{3} \mathrm{C}_{\mathrm{p}}(\lambda, \beta) \mathrm{v}^{2}}{\lambda}
$$

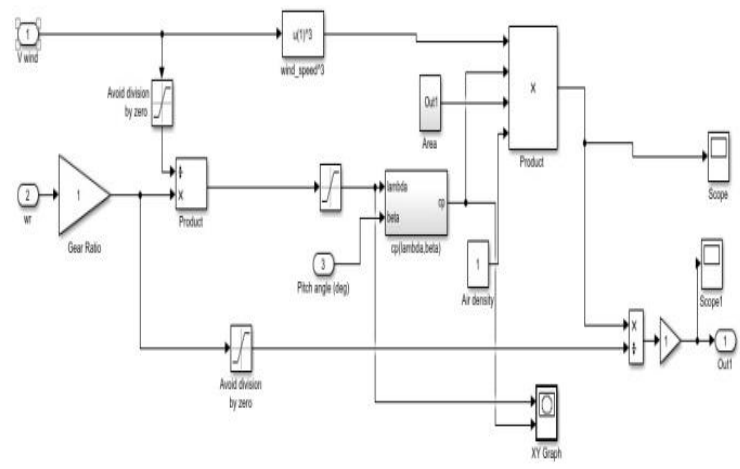

Fig.5.Wind turbine Model in MATLAB/SIMULINK

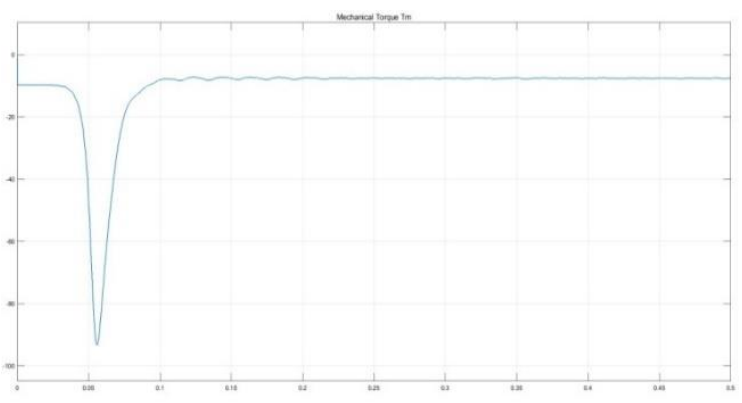

Fig.6.Mechanical Characteristics of Wind Turbine

\section{Model of the Drive Train}

The word drive train plays a vital role in electricity generation with wind energy conversion systems. The drive train is mechanically responsible for converting low-speed rotor turbines to high speeds. Two different speed schemes operate on the drive train a steady speed system and variable speed system. The rotor speed is controlled by grid frequency in the steady speed system. A power converter controls the speed and frequency of the grid in the variable speed system. Therefore, the speed and frequency are coupled in nature. Hence changing the input power will change the output power and speed of the rotor. There is no gearbox for a variable speed system in direct drive wind turbines. The PMSG-based wind turbine is directly linked to the generator with no gearbox the rotation speed could be a small value. Hence direct-drive setup needs to have more pole pairs to produce a high electromagnetic torque.[8]Additional, the drive-train stiffness is reciprocal to the number of generator poles, it indicates that the directdrive scheme has a soft drive-train shaft. The speed of PMSG and the torsional swing of the driving system will cause an electromagnetic pulse which may lead to system instability. Due to the large volume \& size of the PMSG system and its weight, a one-mass drive train model cannot represent vibrant system output. In a direct-drive setup a two-mass model with torsional function is adequate to reflect the dynamic system performance well within the operating phase. By ignoring mechanical losses the drive train can be depicted by the following two-mass model shown in Fig.7[9].

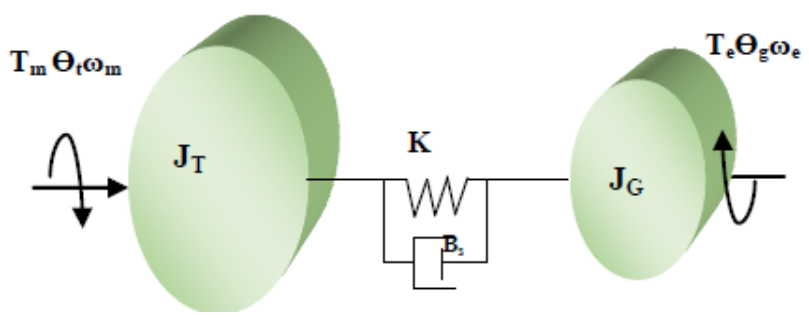

Fig.7.Two Mass model of Drive train

Where:

$\mathrm{J}_{\mathrm{T}}=$ inertia of the wind turbine

$\mathrm{J}_{\mathrm{G}}=$ inertia of the generator

$\omega_{\mathrm{m}}=$ speed of the turbine

$\omega_{\mathrm{e}}=$ speed of the generator

$\mathrm{K}_{\mathrm{s}}=$ stiffness of shaft

$\mathrm{B}_{\mathrm{s}}=$ damping ratio of shaft

$\mathrm{J}_{\mathrm{C}}=$ combined moment of inertia ofthe WTG rotor and PMSG 


$$
\begin{gathered}
J_{T} \omega_{m} \cdot=T_{m}-K_{s}\left(\int \omega_{m}-\omega_{e}\right) d t \\
-B_{s}\left(\omega_{m}-\omega_{e}\right) \\
\mathrm{Jg}_{\mathrm{g}} \cdot \dot{\mathrm{e}}=\mathrm{K}_{\mathrm{s}}\left(\int \omega_{\mathrm{m}}-\omega_{\mathrm{e}}\right) \mathrm{dt}+\mathrm{B}_{\mathrm{s}}\left(\omega_{\mathrm{m}}-\omega_{\mathrm{e}}\right) \\
-\mathrm{T}_{\mathrm{e}}
\end{gathered}
$$

Further the wind turbine rotor dynamics is modeled as

$$
\mathrm{T}_{\mathrm{e}}=\mathrm{T}_{\mathrm{m}}+\mathrm{B}_{\mathrm{S}} \omega_{\mathrm{m}}+\mathrm{J}_{\mathrm{C}} \frac{\mathrm{d} \omega_{\mathrm{m}}}{\mathrm{dt}}
$$
angular speed of the electric machine $\omega_{\mathrm{e}}$, through

$$
\omega_{\mathrm{m}}=\frac{\omega_{\mathrm{e}}}{\mathrm{P}_{\mathrm{p}}}
$$

$\mathrm{P}_{\mathrm{p}}$ is number of generator pole pairs

\section{Modelling of PMSG in MATLAB/SIMULINK}

Permanent magnets create the magnetic field in the rotor of a permanent magnet generator whereas other generators use electromagnets in a rotor winding. The permanent magnet generators do not need a DC supply for the excitation system; so no slip rings \& brush assembly set are required. The integration of variable velocity wind turbines, into the grid, allows wind turbines to operate in wide range of velocity and for each velocity optimal tip speed ratio needs to be achieved.[10]. PMSG can inject power into the electrical network through a completely controlled frequency converter, which consists of a rectifier, a midway DC circuit, and an inverter. The PMSG can be regulated to achieve peak production in the incident air under various load circumstances with the highest effectiveness[11]. The controller can exercise for autonomous active and reactive power control while extricating the notch up power in the wind. The controller controls active and reactive power through the generator side converter and the grid side converter[12]. By regulating the inverter, reactive power can be provided when there is a voltage dip this will help in voltage restoration[13].The benefits of superior efficiencies, low maintenance and no gearbox conditions render permanent magnet generator continuous appealing rather than other generators.

PMSG is doesn't need any external excitation; this makes machine superior with various benefits like amputation of gearbox and absence field winding reduces copper losses.Hence PMSG is more competent when compared to Wound Rotor Synchronous Generators (WRSG). Unlike WRSG no external power supply is needed. The maintenance is eliminated since brushes and slip rings as well as the rotor windings are removed. The common issue with WRSG is the relation between the frequency induced and the mechanical speed of the rotor. When the wind speed varies, the rotor speed also changes and this leads to variations in the frequency of the generated voltage. The major drawback of PMSG is that due to the temperature rise; the permanent magnets can lose its magnetic property partially or fully this needs to be considered while selecting the type of generator. In a partial loss of the magnetic property, magnet field is weak and if there is completely lose in its magnetic property, it necessitates remagnetization which is a tranquil task and, in few machines, it's impossible and this leads to a replacement of rotor or the entire machine. Therefore, a rise in the temperature has to be kept well within safe limits to ensure that the magnet property on the machine in any dreadful condition should be conserved. Further Partial demagnetization is typically a
The rotor mechanical speed, $\omega_{\mathrm{m}}$ which is related to the rotor

situation where sections of the magnets are subjected to strong opposing magnetic fields during a short circuit. Compared to WRSG, the PMSG is better suited for gearless applications. When PMSG \& WRSG are compared for increase in the number of poles pairs, it can be seen that number of pole pairs attain large values, the tallness of WRSG's rotor becomes thicker. This leads to a rise in WRSG's size and weight beyond PMSG. Currently PMSGs are more appealing for direct-driven wind energy systems due to their increased efficiency and lower costs.

Moreover, the PMSG offers several benefits, for example

a) Superior power performance and effectiveness.

b) For excitation of the magnetic field, additional power $\mathrm{s}$ upply is not required.

c) Improved heat dissipation features of the machine owing to removal of field losses.

d) Superior reliability in this system as the mechanical parts like slip rings is not present.

A PMSG can also be modelled using "Park's transformation or reference Frame Theory". R. H. Park in the year 1920 has implemented a techno-machine analysis of synchronous machines the investigated variables such as voltage, currents and flux linked with the stator winding also links with fictional winding factors which rotate with the rotor.[14]. The stator variables were transformed or moved to a reference frame fixed in the rotor [15]. In this way, he learned that the distinctive property was to eliminate all time-varying inductance from synchronous machinery's voltage equation that gets developed owing to relative movement in electrical circuits and variable magnetic reluctance circuit[16]

In two phases' synchronous rotor reference frame q-axis and d-axis, of the permanent magnet synchro generator is represented. The electrical and mechanical model will be used to represent the model proposed A typical synchronous machine with two poles and three phases is illustrated in above Fig.8 The winding 'as', 'bs', 'cs' and 'as ', ' 'bs ${ }^{1}$, ' $\mathrm{cs}^{1}$ ' on the axis are fixed windings of the stator.

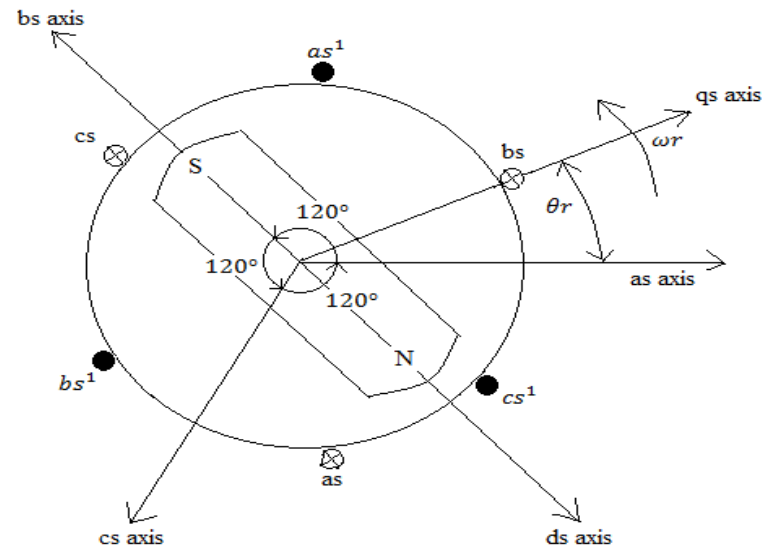

Fig. 8 Two pole, three phase permanent magnet synchronous machine

The crossed circle depicts ' as ', ' bs ' and "cs in the above figure 8 it shows that positive current flows through them (and into the document) while a complete circle with a dots at centre depicts ' as ${ }^{1}$ ', ' bs ${ }^{1}$ ' and "cs ${ }^{1}$ shows negative current flowing passing through them(going out of the paper). 
Applying the generator rule to ' as ' and ' as1 'axis the direction of current in the conductor can be found, similarly for the conductors in ' bs ' and ' cs ' axes can also be acquired using the same technique. [17].

The following hypotheses are:

1. In this machine, there are no damping winding.

2. There is low magnetic saturation.

3. Eddy current and magnetic loss in machine is ignored.

4. Power losses shall be regarded as constant.

5. Alignment of the rotors North Pole is attached to the daxis and q-axis is $90^{\circ}$ preceded by the rotation.

6. The rotational direction is anti-clockwise and the q-axis is $90^{\circ}$ degrees ahead of the d-axis.

Through the arbitrary frame theory with change of the variables that transform a three-phase variable into a stationary circuit element. The arbitrary reference frame is given by,

Considering the stator winding,

$$
f_{d q 0 s}=K_{s} f_{a b c s}
$$

Where, ' $\mathrm{f}$ ' relates to formulation of voltage, current or flux linkage

' $d$ ' relates to direct axis

'q' relates to quadrature axis

' $K_{S}$ ' is the matrix obtained for variable conversion and

$$
\begin{gathered}
\left(f_{d q 0 s}\right)^{T}=\left[f_{q s} f_{d s} f_{0 s}\right] \\
\left(f_{a b c s}\right)^{T}=\left[f_{a s} f_{b s} f_{c s}\right] \\
K_{s} \\
=\frac{2}{3}\left[\begin{array}{ccc}
\operatorname{Cos} \theta & \operatorname{Cos}\left(\theta-\frac{2 \pi}{3}\right) & \operatorname{Cos}\left(\theta+\frac{2 \pi}{3}\right) \\
\operatorname{Sin} \theta & \operatorname{Sin}\left(\theta-\frac{2 \pi}{3}\right) & \operatorname{Sin}\left(\theta+\frac{2 \pi}{3}\right) \\
\frac{1}{2} & \frac{1}{2} & \frac{1}{2}
\end{array}\right]
\end{gathered}
$$

Angular velocity

$$
\omega=\frac{d \theta}{d t}
$$

It can be shown that inverse transformation of equation (17) can be represented by,

$$
\left(K_{S}\right)^{-1}=\left[\begin{array}{ccc}
\operatorname{Cos} \theta & \operatorname{Sin} \theta & 1 \\
\operatorname{Cos}\left(\theta-\frac{2 \pi}{3}\right) & \operatorname{Sin}\left(\theta-\frac{2 \pi}{3}\right) & 1 \\
\operatorname{Cos}\left(\theta+\frac{2 \pi}{3}\right) & \operatorname{Sin}\left(\theta+\frac{2 \pi}{3}\right) & 1
\end{array}\right]
$$

Where angular velocity ' $\omega$ ', and angular displacement ' $\theta$ ' of the arbitrary reference frame are given by the equation (18) shows that

$$
\theta=\int \omega d t
$$

As represented in the equations 15 the term ' $\mathrm{f}$ ' can be symbolized as current, voltage, and electric charge or also as flux linkage. The ' $\mathrm{T}$ ' type indicates as the transpose of anmatrix, and the sub script ' $\mathrm{s}$ ' indicates as variables or factors and the conversion linked with stationary circuits arrangement. In connection with the circuit, the angular displacement ' $\theta$ ' is continuous If it is indeterminate when related to the change in variables. The reference frame is constantly rotated or can be stationary or with varying angular velocity. In the connection with the arbitrary base the fact governs that angular velocity in union with the transformation is not mentioned and can be selected arbitrarily or randomly to find the answer of the system equation and suit the system limitations. The transformation in variables can be implemented in all types of waveform and to any time sequence models where this type of conversion is suitable and it primarily uses ' abc ' sequence.

The conversion equations in an arbitrary reference frame are factors that do not need any physical connotation, and are often easy to evaluate. The trigonometrically association with connecting variables is shown in above Fig.8 Equations used in transformation are given as ' $\mathrm{f}_{\mathrm{qs}}$ ' and ' $\mathrm{f}_{\mathrm{ds}}$ ' which are directed on the path of orthogonal vectors which are revolving at angular velocity of ' $\omega$ ', where as ' $\mathrm{fas}_{\mathrm{as}}$ ' $\mathrm{f}_{\mathrm{bs}}$ ' ' $\mathrm{c}_{\mathrm{cs}}$ ' are the variables which are directed along the stationary paths, displaced $120^{\circ}$ apart from each other.

If the variables in ' $\mathrm{fas}_{\mathrm{as}}$ ' ' $\mathrm{f}_{\mathrm{bs}}$ ' $\mathrm{f}_{\mathrm{cs}}$ ' are considered as fixed but their windings are displaced by $120^{\circ}$ this is also resolved into 'fqs' \& 'fds', but 'fqs' corresponds to the first row of matrix which is obtained as shown in equation (17), the same is achieved when the stationary windings are displaced and these are resolved into ' $\mathrm{f}_{\mathrm{ds}}$ ', the second row of matrix. As an key note to be made as ' $f_{0 s}$ ' variable are not coupled with the arbitrary reference frame study, but the zero variable is related to arithmetically to 'abc' variables, that are independent of ' $\theta$ '. Another point to be taken into consideration ' $\mathrm{fas}_{\mathrm{as}}$ ' ' $\mathrm{f}_{\mathrm{bs}}$ ' ' $\mathrm{f}_{\mathrm{cs}}$ ' are instantaneous quantities they are dependent of time, portraying this conversion as shown in the above figure 8 and it is mostly suitable for applying it to AC machines where the direction is related to ' $\mathrm{f}_{\mathrm{as}}$ ' ' $\mathrm{b}_{\mathrm{bs}}$ ' ' $\mathrm{f}_{\mathrm{cs}}$ ' and also may be considered in the course of magnetic axes of the stator windings. Thus the alignment of ' $\mathrm{f}_{\mathrm{qs}}$ ' and ' $f_{\mathrm{ds}}$ ' is in the direction of magnetic axes of the 'new' windings obtained by the transforming of variables.

Thus the total three phase power in terms of 'abc' variables is

$$
P_{a b c s}=v_{a s} * i_{a s}+v_{b s} * i_{b s}+v_{c s} * i_{c s}
$$

The three-phase power in terms of ' $\mathrm{dq} 0$ ' variables, must be equal to the three-phase power expressed in terms of 'abc' variables, hence substituting the equation (14) into equation (21) gives

$$
P_{d q 0 s}=P_{a b c s}=\frac{3}{2}\left(v_{q s} * i_{q s}+v_{d s} * i_{d s}\right)
$$

The factor $\frac{3}{2}$ comes due to the selection of constants used in the conversion, but the waveform of 'qs' 'ds' currents, voltages, flux linkages and the electric charges are reliant on the angular velocity of the reference frame and the total power is free from of reference frame. Thus the waveform of the total power is same as of the reference frame in when it's evaluated.

For a resistive element of a three phase system is given by,

$$
\begin{aligned}
& V_{a b c}=r_{s} * i_{a b c s} \\
& V_{d q 0 s}=K_{s} r_{s}\left(K_{s}\right)^{-1} * i_{d q 0 s}
\end{aligned}
$$

For a inductive element of a three phase circuit is given by,

Where operator,

$$
V_{a b c}=p * \lambda_{a b c s}
$$

$$
p=\frac{d}{d t}
$$




$$
V_{d q 0 s}=K_{s} p\left[(K s)^{-1} * \lambda_{d q 0 s}\right]
$$

As the main stator winding are assumed combination of resistance and inductance we have adding equation (23) and equation (25)

$$
V_{a b c}=r_{s} * i_{a b c s}+p * \lambda_{a b c s}
$$

and by adding equation (24) and equation (27)

$$
\begin{gathered}
V_{d q 0 s}=K_{s} r_{s}\left(K_{s}\right)^{-1} \\
* i_{d q 0 s}+K_{s} p\left(K_{s}\right)^{-1} * \lambda_{d q 0 s} \\
\left.+K_{s}\left(K_{s}\right)^{-1} * p * \lambda_{d q 0 s}\right] \\
r_{s}=K_{s} r_{s}\left(K_{s}\right)^{-1} \\
\omega_{r}=K_{s} p\left[\left(K_{s}\right)^{-1}\right]
\end{gathered}
$$

where, rotor electrical speed,

$$
\omega_{\mathrm{r}}=\left[\begin{array}{ccc}
-\operatorname{Sin} \theta & \operatorname{Cos} \theta & 0 \\
-\operatorname{Sin}\left(\theta-\frac{2 \pi}{3}\right) & \operatorname{Cos}\left(\theta-\frac{2 \pi}{3}\right) & 0 \\
-\operatorname{Sin}\left(\theta+\frac{2 \pi}{3}\right) & \operatorname{Cos}\left(\theta+\frac{2 \pi}{3}\right) & 0
\end{array}\right]
$$

therefore, multiplying equation (18) and equation (32) we get

$$
K_{s} p\left(K_{s}\right)^{-1}=\omega\left[\begin{array}{ccc}
0 & 1 & 0 \\
-1 & 0 & 0 \\
0 & 0 & 0
\end{array}\right]
$$

from the above equation 3.32 can also be written as

$$
\omega_{r}=\omega\left[\begin{array}{ccc}
0 & 1 & 0 \\
-1 & 0 & 0 \\
0 & 0 & 0
\end{array}\right]
$$

for resistive element $\left[K_{s}\left(K_{s}\right)^{-1}\right]=1$, and substituting ' $\omega_{r}$ '

$$
V_{d q 0 s}=\left[r_{s} * i_{d q 0 s}+p * \lambda_{d q 0 s}+\omega_{r} * \lambda_{d q 0}\right]
$$

from equation (34), the matrix above we

$$
\text { have, }\left[\lambda_{d q 0}\right]^{T}=\left[\begin{array}{ll}
\lambda_{d s}-\lambda_{q s} & 0
\end{array}\right]
$$

Where, (37)

$$
\begin{gathered}
\lambda_{q s}=L_{q s} * i_{q s} . \\
\lambda_{d s}=L_{d s} * i_{d s}+\psi \\
V_{q s}=r_{s} i_{q s}+L_{q s} p * i_{q s}+\omega_{r}\left(L_{d s} i_{d s}+\psi_{f}\right) \\
V_{d s}=r_{s} i_{d s}+L_{d s} p * i_{d s}-\omega_{r} L_{q s} i_{q s} \\
\frac{d i_{q}}{d t}=\frac{1}{L_{q}}\left[-r_{s} i_{q s}-\omega_{r}\left(L_{d s} i_{d s}+\psi_{f}\right)+V_{q s}\right] \\
\frac{d i_{d}}{d t}=\frac{1}{L_{d}}\left[-r_{s} i_{d s}+\omega_{r} L_{q s} i_{q s}+V_{d s}\right]
\end{gathered}
$$

where,

$$
\begin{aligned}
& L_{q}=L_{q s}+L_{l s} \\
& L_{d}=L_{d s}+L_{l s}
\end{aligned}
$$

from equation (21), power is given by,

$$
\begin{gathered}
P_{a b c}=v_{a s} i_{a s}+v_{b s} i_{b s}+v_{c s} i_{c s} . \\
P_{d q}=\frac{3}{2}\left(v_{d s} i_{d s}+v_{q s} i_{q s}\right) \\
P_{e m}=\frac{3}{2}\left(e_{d} i_{d s}+e_{q} i_{q s}\right)
\end{gathered}
$$

where back e.m.f in 'dq' axis is given by,

$$
\begin{gathered}
e_{d}=-\omega_{r} L_{q} i_{q s} \\
e_{q}=\omega_{r}\left(L_{d} i_{d s}+\psi_{f}\right) \\
P_{e m}=\frac{3}{2} \omega_{r}\left(-L_{q s} i_{q s} i_{d s}+i_{q s}\left(L_{d s} i_{d s}+\psi_{f}\right)\right. \\
P_{e m}=\frac{3}{2} \omega_{r}\left(\psi_{f} i_{q s}+\left(L_{d s}-L_{q s}\right) i_{d s} i_{q s}\right)
\end{gathered}
$$

Electromagnetic torque is given by

$$
T_{e}=P_{e m}=\frac{3}{2}\left[\frac{P}{2}\right]\left(\psi_{f} i_{q s}+\left(L_{d s}-L_{q s}\right) i_{d s} i_{q s}\right)
$$

The correlation between rotor electrical speed ' $\omega_{r}$ ' and rotor mechanical speed ' $\omega_{m}$ ' can be articulated as

or

$$
\omega_{e}=\frac{P}{2} \omega_{m}
$$

from equation (20) angular displacement,

$$
\theta=\frac{1}{s} \frac{P}{2} \omega_{m}
$$

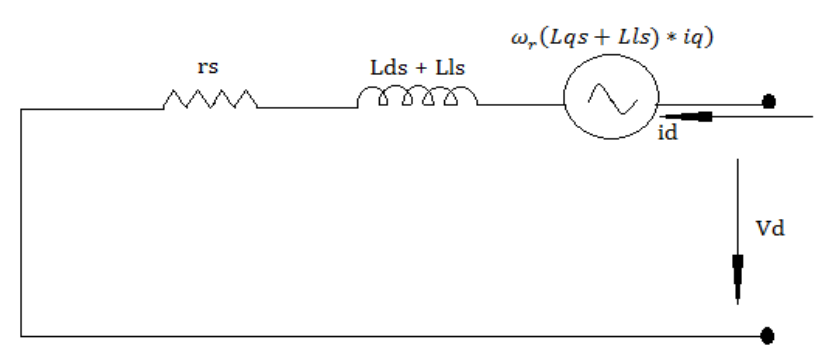

Fig. 9. 'd' axis equivalent circuitmachine

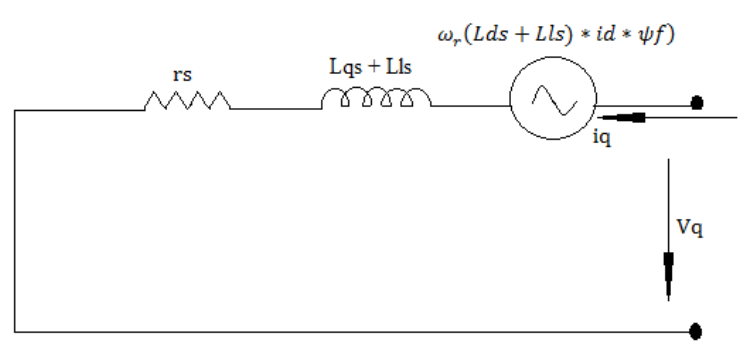

Fig. 10. ' $q$ ' axis equivalent circuit machine

where ' $\omega_{r}$ ' or ' $\omega_{e}$ ' is also called as electrical angular speed ' $\omega_{m}$ ' is also called as mechanical angular speed

' $\mathrm{P}$ ' is the number of poles

As for surface mounted PMSG,

$$
L_{d s}=L_{q s}
$$

therefore, electromagnetic torque

$$
T_{e}=P_{e m}=\frac{3}{2}\left[\frac{P}{2}\right]\left(\psi_{f} i_{q s}\right)
$$

and mechanical torque

$$
T_{m}=T_{e}+B \omega_{m}+J \frac{d \omega_{m}}{d t}
$$

where, ' $T_{m}$ ' is mechanical torque

' $T_{e}$ ' is electromagnetic torque

' $\mathrm{B}$ ' is the friction coefficient

' $\mathrm{J}$ ' Inertia constant

Thus from equation (41) and (42) we have the equivalent circuit for a PMSG as shown in Fig 9\&Fig 10 Thus from the above equivalent circuit we also verify equation (39) and (40) by applying KVL,

$$
\begin{array}{r}
V_{q}=r_{s} i_{q}+L_{q} \frac{d i_{q}}{d t}+\omega_{r} L_{d} i_{d}+\omega_{r} \psi_{f} \\
V_{d}=r_{s} i_{d}+L_{d} \frac{d i_{d}}{d t}-\omega_{r} L_{q} i_{q}
\end{array}
$$

where,

$$
\begin{aligned}
& L_{q}=L_{q s}+L_{l s} \\
& L_{d}=L_{d s}+L_{l s}
\end{aligned}
$$




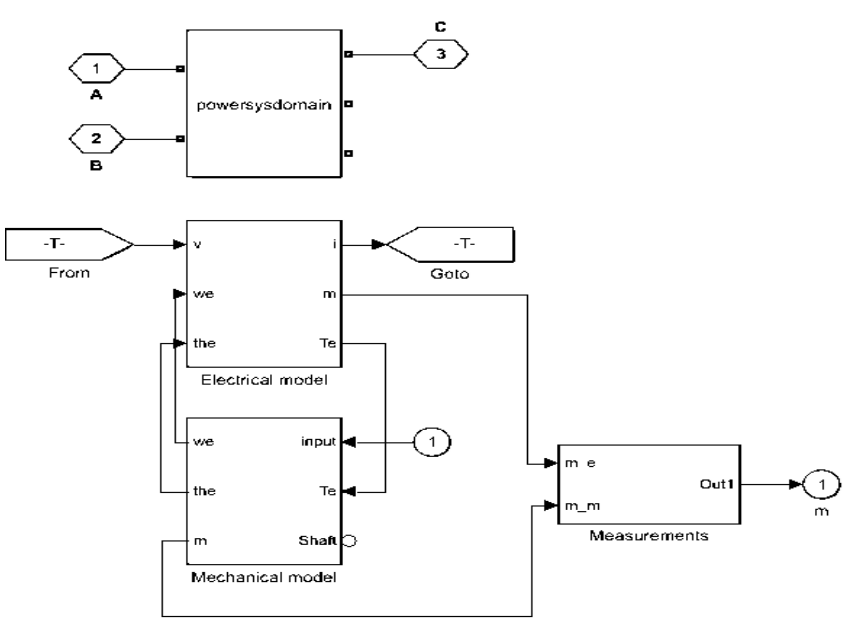

Fig. 11. SIMULINK representation of PMSG

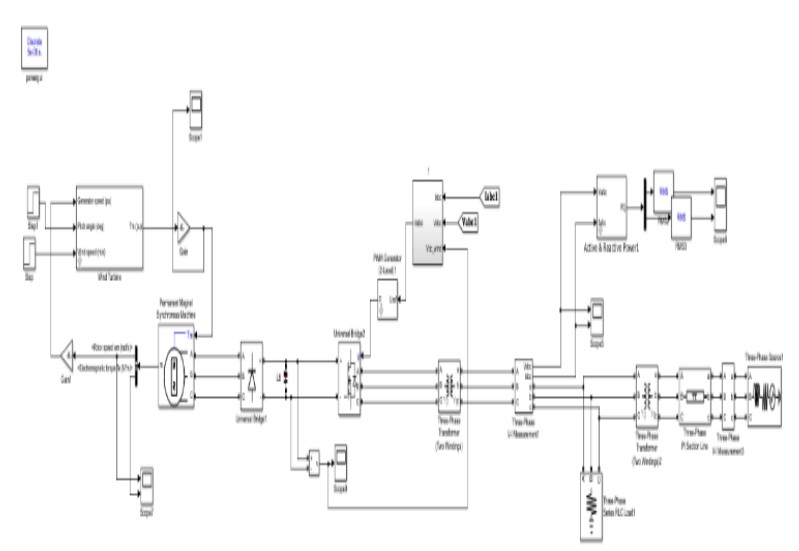

Fig. 12. SIMULINK representation of PMSG based Wind power system Power system

\section{RESULT AND DISCUSSION}

In this renewable energy conversion system, simulations are mainly carried on wind energy conversion system employing Permanent Magnet Synchronous Generator with direct drive technique. These simulations will help in analyzing and designing configurations and control strategy for grid interactive systems. To demonstrate the effectiveness of the technique proposed, various simulation results using MATLAB/SIMULINK are shown with $\mathrm{R}$ load. The output of the wind turbine excited by $12 \mathrm{~m} / \mathrm{s}$ wind velocity will produce a torque which serves as input to the PMSG. Further PMSG is connected to a rectifier which converts the variable AC to DC using bridge rectifier, a RC filter is provided to smoothen out the ripple contents in rectified DC. A MOSFET based three phase inverter is used to obtain the AC voltage. The gate signals to the inverter is obtained by 2 level PWM generator, further the synchronization with the grid is performed with the assistance of three phase lock loop technique. A nonlinear load is connected at PCC the real and reactive power is tabulated for change in load conditions. Further output of the inverter is connected to the grid with the help of step up transformer and short transmission line. Figure no's 13 to 16 shows the waveforms of wind power system.
Fig. 13. DC voltage from the rectifier of wind power system system Power system

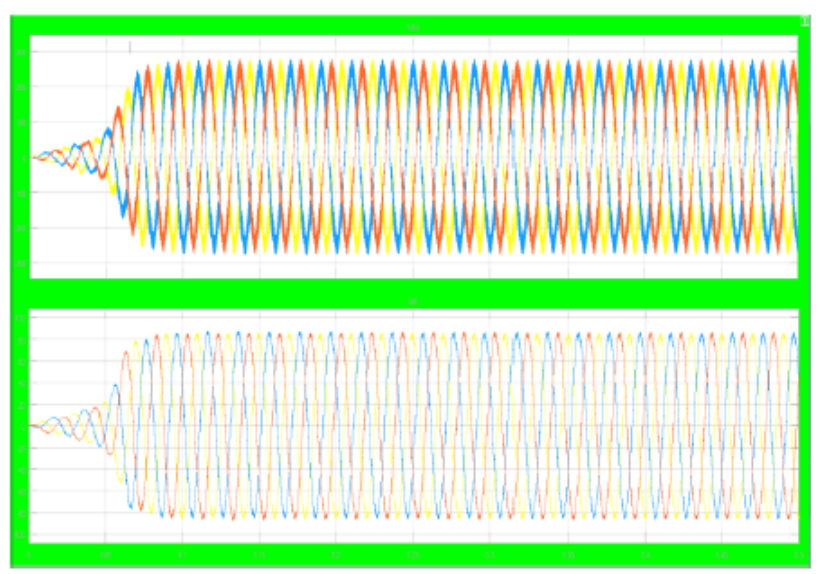

Fig. 14. Three phase voltage and currents of wind power system system Power system

Fig. 15. Real and reactive from wind power system

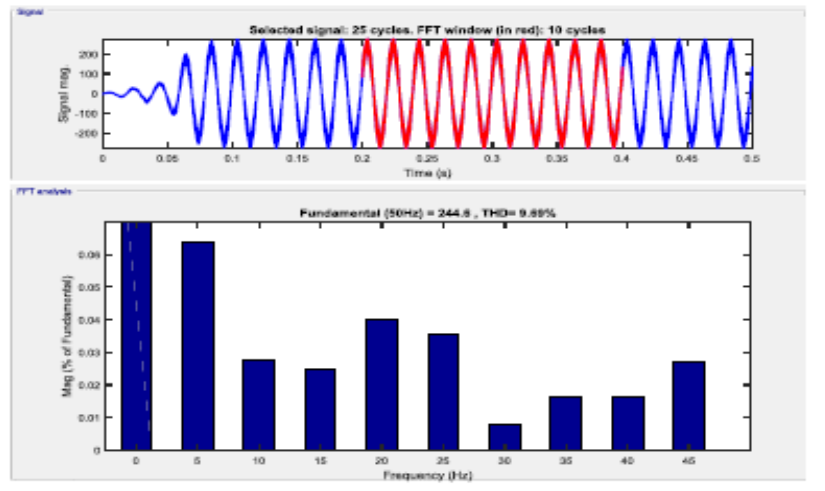

Fig. 16. FFT analysis of voltage from wind power system System Power system

Published By: 


\section{CONCLUSION}

This paper proposes a small $10 \mathrm{~kW}$ wind power system with grid connection and it is modeled in MATLAB/Simulink for rural electrification with an emphasis on the providing power for rural loads.

Growth of a rural electrification sector can be through decentralized electrification. Based on the requirements, this sector considers local resources available, especially wind energy, to define technical configuration suitable for the demand. Thus, we need to conclude through this study that rural electrification by wind energy is the most appropriate solution to cover the needs in energy for such arid areas.

\section{REFERENCES}

1. C. E. Authority, "Large Scale Grid Integration of Renewable Energy Sources - Way Forward," no. November, 2013.

2. [N. D. Karelia and V. J. Pandya, "Distributed Generation and Role of UPQC - DG in meeting Power Quality Criteria - A Review," Procedia Technol., vol. 21, pp. 520-525, 2015.

3. V. Kumar, A. S. Pandey, and S. K. Sinha, "Grid Integration and Power Quality Issues of Wind and Solar Energy System : A Review,' in International Conference on Emerging Trends in Electrical Electronics \& Sustainable Energy Systems (ICETEESES), 2016, vol. 2011, pp. 71-80.

4. Harsh and D. S. K. Singal, "Integration of Renewable Energy Sources Using Artificial Intelligent System," Int. J. Innov. Res. Sci. Eng. Technol., vol. 03, no. 11, pp. 17291-17305, Nov. 2014.

5. J.-Y. Son and K. Ma, "Wind Energy Systems," Proc. IEEE, vol. 105, no. 11, pp. 2116-2131, Nov. 2017.

6. B. Han, H. Lee, and D. Yoon, "Hardware simulator development for PMSG wind power system," in 2009 IEEE Power \& Energy Society General Meeting, 2009, pp. 1-6.

7. M. S. El Moursi and A. M. Sharaf, "Novel STATCOM controllers for voltage stabilisation of wind energy scheme," Int. J. Glob. Energy Issues, vol. 26, no. 3/4, p. 382, 2006.

8. J. Guo and X. Wang, "The speed control of a direct-drive PMSGbased wind energy conversion system," Proc. 2015 27th Chinese Control Decis. Conf. CCDC 2015, no. 2, pp. 1921-1925, 2015.

9. J.Marques, H.Pinheiro, H.A.Gründling, J.R.Pinheiro, and H.L.Hey, "A Survey of Variable-Speed Wind Turbine System," Proc. 7th $\{B\}$ razilian Power Electron. Conf. (COBEP 2003), pp. 732-738, 2003.

10. M. Yin, G. Li, M. Zhou, and C. Zhao, "Modeling of the Wind Turbine with a Permanent Magnet Synchronous Generator for Integration," 2007 IEEE Power Eng. Soc. Gen. Meet., pp. 1-6, 2007.

11. M. Chinchilla, S. Arnaltes, and J. C. Burgos, "Control of permanentmagnet generators applied to variable-speed wind-energy systems connected to the grid," IEEE Trans. Energy Convers., vol. 21, no. 1, pp. 130-135, 2006.

12. J. Dai et al., "A Novel Control Scheme for Current-Source-ConverterBased PMSG Wind Energy Conversion Systems," IEEE Trans. Power Electron., vol. 24, no. 4, pp. 963-972, 2009.

13. A. C., A. C., J. P. A. Vieira, M. V. A. Nunes, and U. H., "Reactive Power Control of Direct Drive Synchronous Generators to Enhance the Low Voltage Ride-Through Capability," in Wind Turbines, InTech, 2011.

14. O. Grigore-Muler and M. Barbelian, "The simulation of a multi-phase induction motor drive," in 2010 12th International Conference on Optimization of Electrical and Electronic Equipment, 2010, vol. 1, pp. 297-306.

15. M. A. A. El Hamied and N. H. E. Amary, "Permanent Magnet Synchronous Generator Stability Analysis and Control," Procedia Comput. Sci., vol. 95, pp. 507-515, 2016.

16. K. Patil and B. Mehta, "Modeling and simulation of variable speed wind turbine with direct drive permanent magnet synchronous generator," in Proceeding of the IEEE International Conference on Green Computing, Communication and Electrical Engineering, ICGCCEE 2014, 2014, pp. 1-6.

17. D. Systems, "Reference-Frame Theory," in Analysis of Electric Machinery and Drive Systems, Hoboken, NJ, USA: John Wiley \& Sons, Inc., 2013, pp. 86-120.

\section{AUTHORS PROFILE}

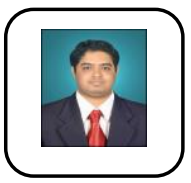

Vinod Shankargouda Patil, is Assistant Professor in the department of Electrical and Electronics Engineering at Jain College of Engineering, Belagavi, Karnataka, INDIA. He obtained his Bachelor of Electrica Engineering from VTU Belagavi in 2008. Master degree in Industrial Electronics from Sri Jayachamarajendra College of Engineering, Manasagangothri, Mysuruin 2010. Pursuing Ph.D. from VTU Belagaviin Electrical Engineering. He is life member of Institute of Engineers (India).

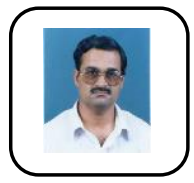

Gopal krishna Dhruvaraj Kamalapur, is Professor in the department of Electrical and Electronics Engineering at SDM College of Engineering and Technology, Dharwad, Karnataka, INDIA. He obtained his Bachelor of Electrical Engineering from Karnataka University in 1984. Master degree in Control Systems from Shivaji University in 1991. Ph.D. from National Institute of Teecnology Karnataka Surathkal in Power systems in 2012. Presently he is guiding three Ph.D. students at Visvesvaraya Technological University, Belagavi, Karnataka and he is awarded with ISTE- Sayed Sajid Ali National Award during 2013. Published 24 papers at International and National Journals and 21 International and National conferences proceedings and life member of ISTE. 